\title{
Growth, Yield and Yield Components of Fine Rice (Oryza sativa L.) as Influenced by Organic Fertilizer
}

\author{
M. R. Islam*, S. Sikder and M. H. R. Hafiz \\ Department of Crop Physiology and Ecology, Hajee Mohammad Danesh Science and Technology \\ University, Dinajpur, Bangladesh \\ *Corresponding author and Email: rabiul_hstu@yahoo.com
}

Received: 04 September 2012 Accepted: 15 November 2012

\begin{abstract}
The experiment was conducted at the Research Farm of Crop Physiology and Ecology Department, Hajee Mohammad Danesh Science and Technology University, Dinajpur, Bangladesh during 14 August to 7 December, 2008 to study the effects of organic fertilizer on yield performance of five fine rice cultivars viz., Rajshahi Swarna, Silkumul, Kataribhog, Lal Pajam and Sanla. The experiment was laid out in a split plot design with three replications. Effective tillers hill ${ }^{-1}$, plant height, panicle length, filled grains panicle ${ }^{-1}$, total grains panicle ${ }^{-1}, 1000$-seed weight, grain yield, straw yield and harvest index (HI) were significantly influenced by the combined effect of cultural conditions and rice cultivars. Under inorganic and organic culture, the highest grain yield was obtained from Rajshahi Swarna (2.90 and $2.74 \mathrm{t} \mathrm{ha}^{-1}$, respectively) and the lowest were from Sanla (2.20 and $1.74 \mathrm{t} \mathrm{ha}^{-1}$, respectively). All the cultivars showed better performance in respect of grain yield and other parameters under inorganic culture than organic culture.
\end{abstract}

Keywords: Cultivar, fine rice, harvest index, organic culture, yield

\section{Introduction}

Rice (Oryza sativa L.) is the second most important cereal crop next to wheat in terms of area and is considered as staple food of a vast majority of people around the world (Rohilla et $a l .$, 2000). In Bangladesh, rice is the first ranking cereal crop in terms of area and production. However, both area and production of transplanted local aman rice (fine aromatic rice and other cultivars) are decreasing. Local aman rice is grown in 1.66 million hectares of land with the production of 1.34 million metric tons (BBS, 2008). Consumer demand for the fine rice varieties is also higher due to its good nutritional quality, palatability, taste, cooking quality and fragrance (Kaul et al., 1982). A good soil should have at least $2.5 \%$ organic matter but in
Bangladesh, most of the soils have less than $1 \%$ organic matter which is also declining day by day (BARC, 2005). Organic fertilizer improves the physical, chemical and biological properties of soil, which increase the soil fertility and productivity. In Bangladesh, many commercial organizations are making nutrient-enriched organic fertilizers, namely Moni Mukta, Agrosar, Jaibo-sar, Super Greenfield, Chook-Chook 111 from cow dung, farmyard manure and poultry manure. These have been evaluated for wetland rice cultivation effectively and could therefore; reduce the use of chemical fertilizer (BRRI, 2004).

Bangladesh has several fine aromatic rice varieties with excellent taste as steamed rice for regular consumption as well as polao, biryani, 
jarda and firni which are served on special occasions. Farmers' reactions are that fine aromatic rice are gradually losing their aroma and other qualities such as yield and taste due to lack of organic matter content in the soil, proper cultural management and changes of environment (Singh and Singh, 1997). The present investigation was therefore, conducted to determine the effects of organic fertilizer on the yield performance of five fine rice cultivars.

\section{Materials and Methods}

The experiment was set up at the Research Farm of Crop Physiology and Ecology Department, Hajee Mohammad Danesh Science and Technology University, Dinajpur, Bangladesh during the aman season (August to December) of 2008. The experiment was laid out in a split plot design with three replications. The unit plot size was $6 \mathrm{~m}^{2} \quad(3 \mathrm{~m} \mathrm{x} 2 \mathrm{~m})$ having a plot to plot and block to block distance of $0.75 \mathrm{~m}$ and $1.0 \mathrm{~m}$, respectively. The main plot treatments were two cultural conditions e.g. Organic and Inorganic culture. The sub-plot treatments were five fine rice cultivars viz. Rajshahi Swarna, Silkumul, Kataribhog, Lal Pajam and Sanla. A fertilizer dose of 90-75-60-60-10 kg NPKSZn ha ${ }^{-1}$ was applied in the form of urea, triple super phosphate, muriate of potash, gypsum, and zinc oxide in the inorganic fertilizer treated plots. In case of organic culture, organic fertilizer of Northern Agro Services Ltd. (NASL) was used at the rate of $2 \mathrm{t} \mathrm{ha}^{-1}$ to fulfill the nutrient requirements. The initial soil $\mathrm{pH}$ was 5.4 to 5.5 having lower organic matter $(1.19 \%)$ content.

Thirty six days old seedlings were transplanted on $14^{\text {th }}$ August 2008 in the main plots. Plant spacing was maintained at $25 \mathrm{~cm} \mathrm{x} 20 \mathrm{~cm}$. Seedlings were transplanted in the field at a rate of 3 seedlings hill $^{-1}$. Weeding and other intercultural operations were done properly but no pesticide and chemical were applied in organic culture.

Number of effective tillers hill ${ }^{-1}$, number of total tillers hill ${ }^{-1}$, plant height $(\mathrm{cm})$, panicle length $(\mathrm{cm})$, number of filled grains panicle ${ }^{-1}$, number of total grains panicle ${ }^{-1}, 1000$-grain weight $(\mathrm{g})$, grain yield $\left(\mathrm{t} \mathrm{ha}^{-1}\right)$ and straw yield $\left(\mathrm{t} \mathrm{ha}^{-1}\right)$ were taken. Harvest index was calculated as: harvest index $(\%)=($ Grain yield $/$ Biological yield $) \mathrm{x}$ 100 (Gardner et al., 1985). All the data were analyzed by partitioning the total variance with the help of a computer program-MSTAT. The treatment means were compared using Duncan's New Multiple Range Test (DMRT) as outlined by Gomez and Gomez (1984).

\section{Results and Discussion}

\subsection{Number of effective tillers hill $^{-1}$}

The combined effect of cultural conditions and cultivars on the number of effective tillers hill ${ }^{-1}$ was significant (Table 1). Under inorganic culture condition, Kataribhog produced the highest number of effective tillers hill ${ }^{-1}$ (11.94), which was followed by Lal Pajam, Silkumul and Sanla (11.32, 11.60 and 10.79, respectively), whereas the lowest number of effective tillers hill $^{-1}$ (9.97) was given by the cultivar Rajshahi Swarna. In organic culture, all the cultivars reduced their effective number of tillers hill ${ }^{-1}$ at various magnitudes compared to inorganic culture. Again, Kataribhog produced the highest number of effective tillers hill ${ }^{-1}$ (10.57) followed by Silkumul and Rajshahi Swarna (10.50 and 9.24 , respectively) and the lowest number of effective tillers hill ${ }^{-1}$ (8.62) was produced by the cultivar Sanla followed by Lal Pajam (9.03). BRRI (1992) reported that the number of effective tillers hill ${ }^{-1}$ produced by some fine rice ranged from 7 to 14 . Hossain (2008) reported that Kataribhog and Badshabhog produced 8.67 and 10.53 effective tillers hill ${ }^{-1}$, respectively under green manuring condition.

\subsection{Total number of tillers hill $^{-1}$}

Differences in total number of tillers hill ${ }^{-1}$ of five fine rice cultivars at different fertilizer conditions was insignificant (Table 1). Under inorganic culture condition, Silkumul was produced the highest number of tillers hill ${ }^{-1}$ (13.20) followed by Kataribhog, Lal Pajam and Sanla (12.98, 12.77 and 12.49 , respectively), whereas the 
lowest number of total tillers hill $^{-1}$ (11.75) attained by the cultivar Rajshahi Swarna. In case of organic culture Silkumul also produced the highest number of total tillers hill ${ }^{-1}$ (13.05) followed by Kataribhog and Lal Pajam (12.53 and 11.32, respectively), whereas the lowest number of total tillers hill ${ }^{-1}$ (11.15) was attained by the cultivar Sanla. Sikdar (2000) showed that cultivar Kalizira, Badshabhog and Tulshimala produced total tillers hill ${ }^{-1}$ of $11.85,10.89$ and 10.41, respectively. Hossain (2008) conducted another investigation and observed that the cultivars Kataribhog and Badshabhog produced total tillers hill $^{-1}$ of 10.20 and 13.27, under organic culture (cow dung @ $10 \mathrm{t} \mathrm{ha}^{-1}$ ).

\subsection{Plant height}

The interaction effect of cultural conditions and cultivars on plant height was significant (Table
1). Under inorganic culture, Kataribhog was the tallest cultivar $(140.9 \mathrm{~cm})$ followed by Silkumul and Sanla (126.6 and $126.1 \mathrm{~cm}$, respectively). The shortest cultivar was Rajshahi Swarna only $(107.8 \mathrm{~cm})$. In organic culture condition, Kataribhog was the tallest $(135.90 \mathrm{~cm})$ cultivar followed by Silkumul, Sanla and Lal Pajam (120.10, 119.10 and $112.80 \mathrm{~cm}$, respectively), and the shortest cultivar was Rajshahi Swarna $(104.50 \mathrm{~cm})$. This difference in plant height among the fine rice cultivars was mostly due to their genetic make up. Sikdar (2000) reported that the inorganic fertilizers significantly influenced the plant height, where Kalizira, Badshabhog and Tulshimala attained the height of $148.96,141.33$ and $151.02 \mathrm{~cm}$, respectively. Hossain (2008) also observed that the cultivars Kataribhog and Badshabhog had height of 138.20 and $134.70 \mathrm{~cm}$, respectively under organic culture (cow dung @ $10 \mathrm{t} \mathrm{ha}^{-1}$ ).

Table 1. Effect of cultural conditions on yield contributing parameters of five fine rice cultivars

\begin{tabular}{|c|c|c|c|c|c|c|c|c|}
\hline Cultivar & $\begin{array}{l}\text { Cultural } \\
\text { condition }\end{array}$ & $\begin{array}{l}\text { Effective } \\
\text { tiller hill }^{-1}\end{array}$ & $\begin{array}{l}\text { Total } \\
\text { tiller } \\
\text { hill }^{-1}\end{array}$ & $\begin{array}{l}\text { Plant } \\
\text { height } \\
(\mathrm{cm})\end{array}$ & $\begin{array}{l}\text { Panicle } \\
\text { length } \\
(\mathrm{cm})\end{array}$ & $\begin{array}{l}\text { Filled } \\
\text { grains } \\
\text { panicle }^{-1}\end{array}$ & $\begin{array}{l}\text { Total } \\
\text { grains } \\
\text { panicle }^{-1}\end{array}$ & $\begin{array}{l}1000- \\
\text { grain } \\
\text { weight } \\
\text { (g) }\end{array}$ \\
\hline \multirow{2}{*}{$\begin{array}{l}\text { Rajshahi } \\
\text { Swarna }\end{array}$} & Inorganic & $9.97 \mathrm{bcd}$ & 11.75 & $107.8 \mathrm{f}$ & $25.65 \mathrm{abc}$ & $181.4 \mathrm{a}$ & $197.8 \mathrm{a}$ & $22.84 b$ \\
\hline & Organic & $9.24 \mathrm{~cd}$ & 11.24 & $104.5 \mathrm{f}$ & $25.25 \mathrm{abc}$ & $171.6 \mathrm{~b}$ & 190.0ab & $22.69 b$ \\
\hline \multirow{2}{*}{ Silkumul } & Inorganic & $11.60 \mathrm{ab}$ & 13.20 & $126.6 \mathrm{c}$ & $24.04 \mathrm{~cd}$ & $170.3 \mathrm{~b}$ & $188.7 \mathrm{ab}$ & $25.09 \mathrm{a}$ \\
\hline & Organic & $10.50 \mathrm{abc}$ & 13.05 & $120.1 \mathrm{~d}$ & $23.45 \mathrm{~d}$ & $160.3 \mathrm{c}$ & $179.7 \mathrm{~b}$ & $24.84 \mathrm{a}$ \\
\hline \multirow{2}{*}{ Kataribhog } & Inorganic & $11.94 \mathrm{a}$ & 12.98 & $140.9 \mathrm{a}$ & $25.87 \mathrm{abc}$ & $161.1 \mathrm{c}$ & $180.4 \mathrm{~b}$ & $14.62 \mathrm{~d}$ \\
\hline & Organic & $10.57 \mathrm{abc}$ & 12.53 & $135.9 \mathrm{~b}$ & $25.83 a b c$ & $150.4 \mathrm{de}$ & $169.7 \mathrm{c}$ & $14.17 \mathrm{~d}$ \\
\hline \multirow{2}{*}{ Lal Pajam } & Inorganic & $11.32 \mathrm{ab}$ & 11.77 & $116.3 \mathrm{de}$ & $24.81 \mathrm{bcd}$ & $159.3 \mathrm{c}$ & $179.4 \mathrm{~b}$ & $18.32 \mathrm{c}$ \\
\hline & Organic & $9.03 \mathrm{~cd}$ & 11.32 & $112.8 \mathrm{e}$ & $24.17 \mathrm{~cd}$ & $146.4 \mathrm{e}$ & $168.4 \mathrm{c}$ & $18.00 \mathrm{c}$ \\
\hline \multirow{2}{*}{ Sanla } & Inorganic & 10.79abc & 12.49 & $126.1 \mathrm{c}$ & $27.05 \mathrm{a}$ & $157.2 \mathrm{~cd}$ & $179.3 \mathrm{~b}$ & $11.23 \mathrm{e}$ \\
\hline & Organic & $8.62 \mathrm{~d}$ & 11.15 & $119.1 \mathrm{~d}$ & $26.52 \mathrm{ab}$ & $144.4 \mathrm{e}$ & $168.4 \mathrm{c}$ & $10.53 \mathrm{e}$ \\
\hline CV (\%) & - & 8.90 & 9.59 & 2.14 & 4.08 & 2.70 & 2.91 & 6.23 \\
\hline
\end{tabular}

Note: Mean followed by same letter(s) did not differ significantly at 5\% level of significance. 


\subsection{Panicle length}

Panicle length was significantly influenced by the cultural conditions and cultivar which is presented in Table 1. Under inorganic culture condition the highest panicle length $(27.05 \mathrm{~cm})$ was found in Sanla followed by Kataribhog and Rajshahi Swarna $(25.87$ and $25.65 \mathrm{~cm}$, respectively), whereas the lowest panicle length $(24.04 \mathrm{~cm})$ was shown by the cultivar Silkumul. On the other hand, under organic culture all the cultivars showed reduced panicle length of various magnitudes compared to inorganic culture. The highest panicle length was found in Sanla $(26.52 \mathrm{~cm})$ which was at par with Kataribhog and Rajshahi Swarna (25.83 and $25.25 \mathrm{~cm}$, respectively). The lower panicle lengths were in Lal Pajam $(24.17 \mathrm{~cm})$ and Silkumul $(23.45 \mathrm{~cm})$. Hossain (2008) observed that the cultivars Kataribhog and Badshabhog produced 21.13 and $20.61 \mathrm{~cm}$ panicle length under green manuring conditions (15 $\left.\mathrm{t} \mathrm{ha}^{-1}\right)$ which was lower than present investigation causing soil and climatic condition of the experimental site.

\subsection{Number of filled grains panicle $e^{-1}$}

The combined effect of cultural conditions and cultivars on filled grains panicle ${ }^{-1}$ was significant (Table 1). Under inorganic culture condition Rajshahi Swarna produced the highest number of filled grains panicle ${ }^{-1}$ (181.40) followed by Silkumul (170.30), whereas the lowest number of filled grains panicle ${ }^{-1}$ was found in Sanla (157.20), which was statistically similar to those of Lal Pajam and Kataribhog (159.30 and 161.10 , respectively). In organic culture, all the cultivars produced lower number of filled grains panicle $^{-1}$ compared to inorganic culture. Rajshahi Swarna produced the highest number (171.60) of filled grains panicle ${ }^{-1}$, followed by Silkumul (160.30). The lowest number of filled grains panicle $^{-1}$ was found in Sanla (144.40) which was statistically similar to that of Lal Pajam (146.40). Chander and Pandey (1996) showed that the application of inorganic fertilizer resulted in significant increase in filled grains panicle ${ }^{-1}$ compared to organic fertilizer, which is consistent with the present findings.

\subsection{Number of total grains panicle ${ }^{-1}$}

The significant variation in number of total grains panicle ${ }^{-1}$ of five fine rice cultivars at different cultural conditions is shown in Table 1 . Under inorganic culture, Rajshahi Swarna produced the highest number (197.80) of total grains panicle ${ }^{-1}$ followed by Silkumul and Kataribhog (188.70 and 180.40, respectively), whereas the lowest number of total grains panicle $^{-1}$ was found in Sanla (179.30) followed by Lal Pajam (179.40). In organic culture, all the cultivars had reduced number of total grains panicle $^{-1}$ compared to inorganic culture. Rajshahi Swarna produced the highest number (190.00) of total grains panicle $e^{-1}$ followed by Silkumul (179.70), whereas the lowest number of total grains panicle ${ }^{-1}$ was found in Sanla (168.40).

\subsection{Weight of 1000-grain}

There was no difference between two cultural conditions in weight of 1000-grain though the cultivars significantly varied (Table 1). Under inorganic culture, the highest 1000 -grain weight was produced by Silkumul $(25.09 \mathrm{~g})$ followed by Rajshahi Swarna (22.84 g) due to their medium bold grain size. The lowest 1000-grain weight was found in Sanla (11.23 g) corresponding to Kataribhog and Lal Pajam (14.62 and 18.32 g, respectively) because of their longer fine grains. Under organic culture, the highest 1000-grain weight $(24.84 \mathrm{~g})$ was produced by Silkumul followed by Rajshahi Swarna (22.69 g) and the lowest 1000-grain weight (10.53 g) was in Sanla. Chowdhury et al. (1993) stated that the cultivar BR23 showed superior performance to Pajam in respect of 1000-grain weight and Hossain (2008) found that 1000-seed weight of Kataribhog and Badshabhog were 13.60 and $9.96 \mathrm{~g}$, respectively under organic culture.

\subsection{Grain yield}

The combined effect of cultural conditions and cultivars on grain yield was significant (Table 2). Under inorganic culture condition, the highest 
grain yield was produced by Rajshahi Swarna (2.90 $\left.\mathrm{t} \mathrm{ha}^{-1}\right)$, which was at par with that of Silkumul and Kataribhog (2.85 t ha ${ }^{-1}$ and $2.71 \mathrm{t}$ $\mathrm{ha}^{-1}$, respectively). The lowest grain yield was produced by Sanla $\left(2.20 \mathrm{t} \mathrm{ha}^{-1}\right)$. Under organic culture, all the cultivars showed reduced grain yield compared to that of inorganic culture. The highest grain yield also found in Rajshahi Swarna $\left(2.74 \mathrm{t} \mathrm{ha}^{-1}\right)$ followed by Silkumul and Kataribhog (2.44 t ha and $2.32 \mathrm{t} \mathrm{ha}^{-1}$, respectively), whereas the lowest grain yield was found in Sanla $\left(1.74 \mathrm{t} \mathrm{ha}^{-1}\right)$ corresponding with Lal Pajam (2.28 t ha-1). BRRI (1999) reported that the fine grain aromatic rice cultivars viz. Khaskani, Basmati-D and Kataribhog produced grain yield 2.81, 2.75 and $2.04 \mathrm{t} \mathrm{ha}$, respectively. Kabir et al. (2004) found that the fine aromatic rice cultivars Begunbitchi, Kalijira and Chinigura-1 produced grain yield of 0.85 , 2.08 and 2.30 tons $^{-1}$. Hossain (2008) reported that Kataribhog and Badshabhog produced yield of 2.30 and 2.12 tons $\mathrm{ha}^{-1}$, respectively. These are in agreement with the present study.

\subsection{Straw yield}

There was a significant variation in straw yield of five fine rice cultivars at different cultural conditions as shown in Table 2. Under inorganic culture condition, the highest straw yield was produced by Rajshahi Swarna (10.28 $\left.\mathrm{t} \mathrm{ha}^{-1}\right)$ followed by Silkumul and Kataribhog $\left(9.70 \mathrm{t} \mathrm{ha}^{-1}\right.$ and $9.62 \mathrm{t} \mathrm{ha}^{-1}$, respectively). Under organic culture, the highest straw yield was found in Rajshahi Swarna (9.83 $\mathrm{t} \mathrm{ha}^{-1}$ ) closely followed by Silkumul and Kataribhog (9.66 t ha ${ }^{-1}$ and 9.48 $\mathrm{t} \mathrm{ha}^{-1}$, respectively) and the lowest grain yield produced by Sanla $\left(8.60 \mathrm{t} \mathrm{ha}^{-1}\right)$.

\subsection{Harvest index}

The harvest index (HI) was significantly influenced by the combined effect of cultural conditions and cultivars which is presented in Table 2. Under inorganic culture condition, the cultivars Rajshahi Swarna, Silkumul and Kataribhog attained very similar harvest index. Silkumul had the highest HI (22.02\%), whereas the cultivar Sanla showed the lowest $(20.15 \%)$. Under organic culture, all the cultivars had reduced $\mathrm{HI}$ compared to inorganic culture except in Rajshahi Swarna. The HI value for Rajshahi Swarna, Lal Pajam, Silkumul, Kataribhog, and Sanla were 21.82, 20.34, 20.16, 19.66 and $16.84 \%$, respectively.

Table 2. Effect of cultural conditions on yield and harvest index of five fine rice cultivars

\begin{tabular}{lllll}
\hline Cultivar & Cultural condition & $\begin{array}{c}\text { Grain yield } \\
\left(\mathrm{t} \mathrm{ha}^{-1}\right)\end{array}$ & $\begin{array}{c}\text { Straw yield } \\
\left(\mathrm{t} \mathrm{ha}^{-1}\right)\end{array}$ & $\begin{array}{c}\text { Harvest Index } \\
(\%)\end{array}$ \\
\hline \multirow{2}{*}{$\begin{array}{l}\text { Rajshahi } \\
\text { Swarna }\end{array}$} & Inorganic & $2.90 \mathrm{a}$ & $10.28 \mathrm{a}$ & $22.02 \mathrm{a}$ \\
Silkumul & Organic & $2.74 \mathrm{ab}$ & $9.83 \mathrm{ab}$ & $21.82 \mathrm{a}$ \\
& Inorganic & $2.85 \mathrm{a}$ & $9.70 \mathrm{ab}$ & $22.74 \mathrm{a}$ \\
Kataribhog & Organic & $2.44 \mathrm{ab}$ & $9.66 \mathrm{abc}$ & $20.16 \mathrm{ab}$ \\
& Inorganic & $2.71 \mathrm{ab}$ & $9.62 \mathrm{abc}$ & $22.00 \mathrm{a}$ \\
Lal Pajam & Organic & $2.32 \mathrm{abc}$ & $9.48 \mathrm{abcd}$ & $19.66 \mathrm{ab}$ \\
& Inorganic & $2.44 \mathrm{ab}$ & $9.46 \mathrm{abcd}$ & $20.49 \mathrm{ab}$ \\
Sanla & Organic & $2.28 \mathrm{abc}$ & $8.94 \mathrm{bcd}$ & $20.34 \mathrm{ab}$ \\
\hline CV (\%) & Inorganic & $2.20 \mathrm{bc}$ & $8.74 \mathrm{~cd}$ & $20.15 \mathrm{ab}$ \\
\hline Ne: & Organic & $1.74 \mathrm{c}$ & $8.60 \mathrm{~d}$ & $16.84 \mathrm{~b}$ \\
\hline
\end{tabular}

Note: Mean followed by same letter(s) did not differ significantly at 5\% level of significance. 


\section{Conclusions}

From the results of this study it might be concluded that all the cultivars showed better performance under inorganic culture in respect of yield and other attributes. However, the yield variation was minimum in between the two cultural conditions. Based on yield characters, Rajshahi Swarna showed superior performance followed by Silkumul, Kataribhog and Sanla.

\section{References}

Bangladesh Agricultural Resaerch Council. 2005. Fertilizer Recommendation Guide. Soils Pub. no 45. BARC, Farmgate, Dhaka, 58-70 pp.

Bangladesh Bureau of Statistics. 2008. Agriculture Wing [online]. In: http://www.bbs.gov.bd (last update 2008; accessed 18 July 2008). People's Republic of Bangladesh, Dhaka.

Bangladesh Rice Research Institute (BRRI). 1992. Annual Internal Review. BRRI, Joydebpur, Gazipur, Bangladesh, 1-18 pp.

Bangladesh Rice Research Institute (BRRI). 1999. Annual Report for January 1998June 1999.. BRRI, Joydebpur, Gazipur, Bangladesh, 9-35 pp.

Bangladesh Rice Research Institute (BRRI). 2004. Annual Internal Review held on 26-29 December. BRRI, Joydebpur, Gazipur, Bangladesh, 23-30 pp.

Chander, S. and Pandey, J. 1996. Effect of herbicide and nitrogen on yield of scented rice cultivars. Indian Journal of Agronomy, 41:209-214.

Chowdhury, M. J. U., Sarker, M. A. R. and Kashem, M. A. 1993. Effect of variety and number of seedlings hill ${ }^{-1}$ on the yield and its components of late transplanted aman rice. Bangladesh Journal of Agricultural Science, 20(2): 311-316.
Gardner, F. P. Pearce, R. B. and Mitchell, R.L. 1985. Physiology of Crop Plants. Iowa State Univ. Press, Iowa.

Gomez, K. A. and Gomez, A. A.1984. Statistical Procedure for Agricultural Research. International Rice Research Institute (IRRI), Los Banus, Philippines. John Wiley and Sons, New York, 139-240 pp.

Hossain, M. F. 2008. Improving the yield and quality of aromatic rice through manipulation of cultural practices. Ph.D. dissertation. Bangladesh Agricultural University (BAU), Mymensingh, Bangladesh, 126-130 pp.

Kabir, M. E., Kabir, M. R. Jahan, M. S. and Das, G. G. 2004. Yield performance of three aromatic fine rice in a coastal medium high land. Asian Journal of Plant Science, 3(5): 561-563.

Kaul, A. K., Khan, M. R. I. and Munir, K. M. 1982. Rice quality: A survey of Bangladesh Germplasm. Bangladesh Rice Research Institute (BRRI), Joydebpur, Gazipur, Bangladesh, 1-178 pp.

Rohilla, R., Singh, V. P., Singh, U. S., Singh, R. K. and Khush, G. S. 2000. Crop husbandry and environment factors affecting aroma and other quality traits. p. 201-216. In D.P. Singh and U.N. Verma (ed.), Aromatic Rice, Oxford and IBH Publishing Company Private Limited, New Delhi.

Sikdar, M. S. I. 2000. Effect of spacing and nitrogen fertilizer level on the yield and quality of some varieties of aromatic rice. M. Sc. Dissertation. Bangladesh Agricultural University, Bangladesh, 1$126 \mathrm{pp}$.

Singh, R. K. and Singh, U. S. 1997. 'Indigenous Scented Rices: Farmers Perception and Commitment'. Paper presented at International Conference on Creativity and Innovation at Grassroots, January 1417, 1997 at 11 am, Hyderabad, India. 